\title{
Grupo de adesão ao tratamento: espaço de "ensinagem" para profissionais de saúde e pacientes
}

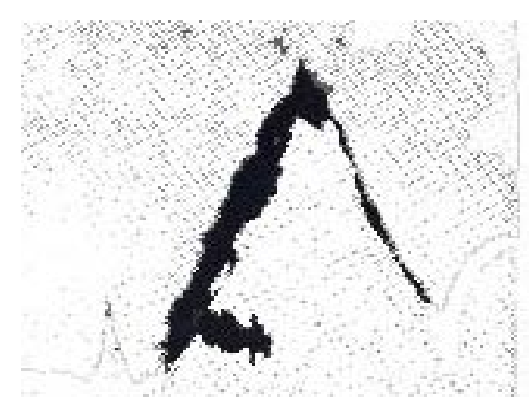

\author{
Lia Márcia Cruz da Silveira ${ }^{1}$ \\ Victoria Maria Brant Ribeiro
}

\begin{abstract}
SILVEIRA, L. M. C.; RIBEIRO, V. M. B. Compliance with treatment groups: a teaching and learning arena for healthcare professionals and patients, Interface - Comunic., Saúde, Educ., v.9, n.16, p.91-104, set.2004/fev.2005.
\end{abstract}

This article presents a healthcare practice - the Compliance with Treatment Group - that provides a potential treatment, teaching and learning arena for patients and healthcare professionals, a stage for the interaction of different people, concepts, values and cultures, in which each player is at once unique but able to see himself in others, through dynamics that enable talking, listening, feeling, questioning, reflecting and learning to think. Its chief characteristic is being an informative and reflexive support group that is homogeneous where the diseases of the participating patients are concerned, under the coordination of two or more healthcare professionals from different categories, whose objective is to make it easier for patients to comply with treatment through dialogue. The study presents an analysis of the work carried out with groups of patients suffering from chronic illnesses and stresses the use of group practice as a therapeutic setting and an arena where patients and healthcare professionals teach and learn. It emphasizes the pedagogical aspects of this practice by encouraging learning through contact with problem situations. This enables adding political, ethical, economic, affective, social and cultural dimensions to current specific knowledge (the health issue). The article also points out the possibility of using this technique for developing communication and work team practices in the field of healthcare education.

KEY WORDS: Practices in group therapy; treatment adherence; teaching and learning space; health multidisciplinary team.

O artigo apresenta uma prática de atenção à saúde - Grupos de Adesão ao Tratamento - que tem evidenciado um campo potencial de terapêutica, de ensino e de aprendizagem para pacientes e profissionais de saúde. Trata-se de cenário de interação de diferentes pessoas, conceitos, valores e culturas no qual cada ator se diferencia e se reconhece no outro em dinâmicas que possibilitam falar, escutar, sentir, indagar, refletir e aprender a pensar. Caracteriza-se por ser um grupo informativo, reflexivo e de suporte, homogêneo quanto à enfermidade dos pacientes, coordenado por dois ou mais profissionais de saúde de diferentes categorias que, pelo método dialógico, têm por objetivo facilitar a adesão dos pacientes ao tratamento. O estudo apresenta uma análise do trabalho com grupos de pacientes com doenças crônicas e ressalta a utilização da prática grupal como cenário de terapêutica e de ensino e aprendizagem para pacientes e profissionais de saúde. Enfatiza o aspecto pedagógico desta prática por propiciar a aprendizagem pelo contato com situações-problema que permitem agregar ao conhecimento específico a questão saúde - dimensões políticas, éticas, econômicas, afetivas e sócio-culturais. Aponta-se a possibilidade da utilização desta prática para desenvolver competências comunicativas e de trabalho em equipe no campo da educação em saúde.

PALAVRAS-CHAVE: Prática grupoterápica; adesão ao tratamento; equipe muldisciplinar em saúde; espaço de "ensinagem".

${ }^{1}$ Professora, Universidade do Grande Rio (UNIGRANRIO); bolsista CAPES <lia.silveira@uol.com.br>

2 Professora, Núcleo de Tecnologia Educacional para a Saúde, Universidade Federal do Rio de Janeiro (NUTES/UFRJ); pesquisadora CNPq. <victoria@nutes.ufrj.br>

${ }^{1}$ Av. Major Frazão, 181, 5ำ andar Duque de Caxias - Rio de Janeiro, RJ 25.071-200 


\section{Introdução}

Muito se tem discutido, atualmente no Brasil, sobre como produzir estratégias educacionais que repercutam na formação provocando mudanças substanciais na prática dos profissionais de saúde, coerentes com os princípios preconizados pelo Sistema único de Saúde (SUS).

\footnotetext{
Pode-se dizer que existe quase uma exigência social de que se mude o processo de formação para que se produzam profissionais diferentes, com formação geral, capazes de prestar uma atenção integral e humanizada às pessoas, que trabalhem em equipe, que saibam tomar decisões considerando não somente a situação clínica individual, mas o contexto em que vivem os pacientes, os recursos disponíveis, as medidas mais eficazes. (Feuerweker, 2001, p.12)
}

Na realidade, a formação do profissional de saúde tem sido orientada por um modelo de atenção biologista fundamentado no paradigma positivista da ciência, cuja racionalidade sustenta-se na fragmentação, no aprofundamento e na descrição de partes para se compreender a unidade humana.

Este modelo deu origem a "preceitos especializantes, nos quais a tecnologia avançou muito sobre as partes, mas perdeu a perspectiva do indivíduo como um todo" (Rodrigues, 1979, p.25). E esta tem sido a racionalidade preponderante na formação profissional que, embora tenha potencialidades e em um dado momento tenha sido fundamental para os avanços que hoje temos no campo da saúde, também tem seus limites. Isto porque, na busca da clareza e do sentido unívoco, "desvaloriza a diversidade, a singularidade, a interação das diferentes dimensões que compõem o sujeito" (Deveza, 1983, p.82), reduzindo os eventos de saúde e doença à dimensão biológica.

Este paradigma epistemológico, orientador do modelo de formação do profissional de saúde, repercute diretamente na sua prática laboral, mostrando-se pouco resolutiva, impessoal, desvinculada da realidade das condições de vida da população e reducionista à medida que coloca como foco de atenção a doença e não os sujeitos que adoecem. Isto sinaliza que, para transformar o processo de formação dos profissionais da saúde, colocam-se como estratégicas a reflexão e a discussão dos diferentes elementos que dão substrato a este processo, dos quais destaca-se, em especial, o homem, objeto de estudo ao qual se destina a formação. Destacam-se também entre estes elementos: o conceito de saúde, o processo saúde/doença, as práticas assistenciais, os espaços onde se desenvolvem e os sujeitos nelas envolvidos, criando um campo propício ao rompimento da clivagem teoria - prática e fomentando uma articulação transformadora que se configure em um novo cenário de atenção à saúde.

Caracteriza este novo cenário a integração do cuidado e da aprendizagem na qual desenvolvam-se: ações de saúde adequadas e compatíveis com e para o homem na sua totalidade e que aproximem os atores envolvidos; práticas que utilizem métodos de trabalho nos quais o cotidiano das pessoas adoecidas esteja presente na cena, com base nas experiências delas mesmas;

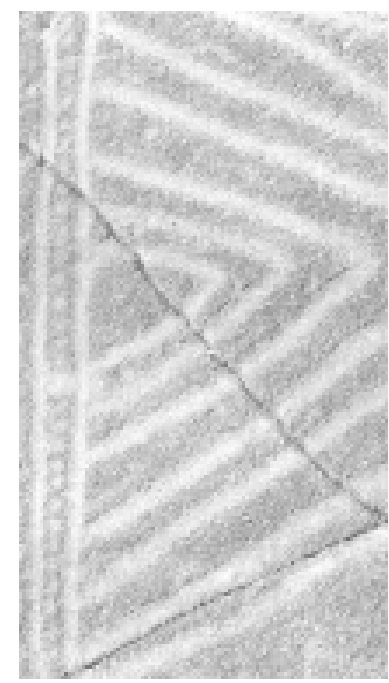


situações que favoreçam a detecção de problemas, o desvelamento de contradições e conflitos, permitam maior visibilidade das necessidades existentes e a busca de superação das dificuldades relacionadas ao cuidado à saúde; oportunidades que propiciem o diálogo para que os indivíduos explicitem suas reais dificuldades e a percepção dos recursos que dispõem para lidar com a situação de sofrimento; situações freqüentes que coloquem equipe de saúde e paciente em uma relação direta, e que estimulem o compromisso e a implicação de ambos na busca de soluções para os problemas de saúde. Em síntese, cenários e procedimentos metodológicos que permitam consolidar uma concepção do homem em sua integralidade, ampliar o foco na compreensão do processo saúde/doença, e que dêem sustentabilidade a uma formação em saúde mais reflexiva, integrada, humanizada, possibilitando pensar o homem de modo mais contextualizado, sem dissociar a história da pessoa do seu processo saúde/doença.

É nesta perspectiva que, neste ensaio, apresentamos uma reflexão teórica do método utilizado em experiência de trabalho com grupo de pacientes crônicos, denominada grupo adesão, realizada em ambulatório de um Hospital Universitário e que, ao acontecer, tem se configurado um campo potencial de terapêutica, de ensino e de aprendizagem para pacientes e para os profissionais de saúde.

\section{Sobre adesão}

$O$ adoecimento traz para o ser humano, em maior ou menor escala, apreensão e ameaça, podendo produzir desequilíbrio e desconforto que levam o homem a debruçar-se sobre o limite de sua própria condição, indagar-se sobre ela e pensar na vulnerabilidade, na finitude e na imprevisibilidade, implícitas no ato de viver. Sanada a situação de adoecimento, o indivíduo se reequilibra e, como é próprio da condição humana, busca neste equilíbrio restabelecer o sentimento de invulnerabilidade que o faz sentir-se forte para lidar com as adversidades da vida. Mas, quando as doenças são denominadas crônicas, de longa duração, o equilíbrio está em viver e conviver autonomamente com esta condição, pois não se curam com remédios; como a própria expressão nos diz, elas são "remediadas, e quando tratadas como uma condição também crônica é passível de duas formas de dependência: a dos remédios e a do médico" (Mello Filho, 2000, p.25). Assim, o tratamento do paciente portador de doença crônica deve favorecer a adaptação a esta condição, instrumentalizando-o para que, por meio de seus próprios recursos, desenvolva mecanismos que permitam conhecer seu processo saúde/doença de modo a identificar, evitar e prevenir complicações, agravos $e$, sobretudo, a mortalidade precoce. Neste sentido, inclui-se no tratamento um item significativo, de relevância para o sucesso do cuidado e que representa um desafio para ambos - profissionais e pacientes - pelo intrincado de variáveis que traz em si, que é a adesão ao tratamento.

No campo da saúde, adesão corresponde ao "grau de seguimento dos pacientes à orientação médica" (Fletcher et al., 1989, p.7), e relaciona-se à maneira como o indivíduo vivencia e enfrenta o adoecimento. Segundo Botega (2001, p.49) "(...) devemos conceber adesão ao tratamento como um processo, com três componentes principais: a noção de doença que 
possui o paciente, a idéia de cura ou de melhora que se forma em sua mente, o lugar do médico no imaginário do doente". Usualmente, quando se pensa em adesão o foco é no paciente, no uso que faz dos medicamentos prescritos, no seguimento das orientações e restrições indicadas, nas modificações que necessita fazer no estilo de vida para equilibrar sua saúde. Há ainda, por parte dos profissionais, preocupação de que as orientações sejam as mais adequadas possíveis visando resultados benéficos para a saúde dos pacientes. Em função deste objetivo, utilizam diferentes métodos para medir adesão: comportamentais (contagem de pílulas, por exemplo), inquérito com os pacientes, relatos colaterais, técnicas bioquímicas, revisão de resultados clínicos, entre outros. Essa forma de avaliar, em que a maioria dos indicadores está relacionada ao aspecto medicamentoso, evidencia uma preocupação com a adesão aos medicamentos em lugar da adesão ao tratamento como se fossem fatores dissociados. Esta compreensão do profissional é norteada por um modelo de atenção à saúde que privilegia a doença e não o doente com suas características, seu estilo e seu contexto de vida, o significado que a doença tem para ele, além de desconsiderar a devida relevância que, neste processo, tem suas relações com a pessoa assistida $e$ com a instituição à qual está vinculada para tratar-se.

Adesão, do latim adhaesione, significa, do ponto de vista etimológico, junção, união, aprovação, acordo, manifestação de solidariedade, apoio; pressupõe relação e vínculo. Adesão ao tratamento é um processo multifatorial que se estrutura em uma parceria entre quem cuida e quem é cuidado; diz respeito, à freqüência, à constância e à perseverança na relação com o cuidado em busca da saúde. Portanto, o vínculo entre profissional e paciente é fator estruturante e de consolidação do processo, razão pela qual deve ser considerado para que se efetive.

Sob este ponto de vista, adesão ao tratamento inclui fatores terapêuticos e educativos relacionados aos pacientes, envolvendo aspectos ligados ao reconhecimento e à aceitação de suas condições de saúde, a uma adaptação ativa a estas condições, à identificação de fatores de risco no estilo de vida, ao cultivo de hábitos $e$ atitudes promotores de qualidade de vida $e$ ao desenvolvimento da consciência para o autocuidado. Considera, também, fatores relacionados ao(s) profissional(is), comportando ações de saúde centradas na pessoa e não exclusivamente nos procedimentos, que aliam orientação, informação, adequação dos esquemas terapêuticos ao estilo de vida do paciente, esclarecimentos, suporte social e emocional.

Nesta perspectiva de ação, a atitude acolhedora do profissional que cuida respalda o paciente para novas atitudes perante o adoecimento, $e \mathrm{o}$ medicamento é mais um recurso terapêutico na promoção da saúde. Há também fatores ligados à instituição de saúde, cuja finalidade é promover e estimular ações que contribuam para que os indivíduos envolvidos possam caminhar em direção à eficácia e à qualidade do tratamento.

Por tratar-se de um processo no qual os sujeitos estão em contato com uma variedade de fatores que influenciam sua continuidade ou a descontinuidade, facilitar a adesão e aderir ao tratamento não são tarefas fáceis; são desafios que sofrem oscilações e demandam atenção contínua.

Pelo entendimento da complexidade do processo e pela amplitude 
requerida no manejo da adesão, faz-se oportuno um outro momento, além da consulta individual, para discussão, esclarecimento e reforço da necessidade de incorporar este tipo de cuidado à vida dos pacientes. Daí a estratégia do grupo de adesão ao tratamento, um espaço solidário que permite o acesso à informação, a troca de experiências, o intercâmbio de motivações, o apoio mútuo e a vivência de uma pluralidade de situações que criam oportunidades para pacientes e profissionais de saúde posicionarem-se, tirarem dúvidas, interagirem e superarem dificuldades no processo de tratamento.

\section{O Grupo de Adesão ao tratamento}

Grupo adesão é uma prática de saúde que se fundamenta no trabalho coletivo, na interação e no diálogo. Trata-se de um grupo homogêneo quanto à enfermidade dos pacientes, aberto com relação à entrada destes em cada reunião e multidisciplinar no que diz respeito à coordenação. Tem caráter informativo, reflexivo e de suporte, e sua finalidade é identificar dificuldades, discutir possibilidades e encontrar soluções adequadas para problemáticas individuais e/ou grupais que estejam dificultando a adesão ao tratamento.

É um ambiente de motivação para o tratamento pelo compartilhar de dificuldades e pela busca de alternativas para superá-las, de construção de vínculos, de acolhida, de respeito à diferença e de reforço da auto-estima, em que se busca estimular a pessoa a encontrar recursos para lidar com as questões do adoecer, da doença e dos seus efeitos sobre sua vida.

É um cenário de interação de diferentes pessoas, conceitos, valores e culturas no qual cada ator se diferencia e se reconhece no outro em uma dinâmica que possibilita falar, escutar, sentir, indagar, refletir e aprender a pensar para superar resistências à mudança $e$ promover adaptação do estilo de vida à condição de saúde. Marca sua diferença do tratamento psicológico grupal por constituir um grupo terapêutico, centrado na tarefa de tomar consciência da necessidade do cuidado e de promover o autocuidado, no qual busca-se identificar obstáculos que impedem o encontro de soluções para o processo de adesão ao tratamento. Mas também é um grupo de ensino e de aprendizagem pelo que se "aprende ali no dia-a-dia, cada um ensinando ao outro o que sabe sobre a sua doença, pelas trocas de experiências que enriquecem, previnem iatrogenias, fortalecem as pessoas para os futuros embates" (Mello Filho, 2000, p.16). Portanto, é um grupo em que o cuidado está presente na ação pedagógica e na ação terapêutica e que funciona estruturado no princípio que afirma que "toda aprendizagem bem realizada e toda educação [são] sempre, implicitamente, terapêuticas” (Bleger, 1998, p.63).

Trata-se, portanto, de um trabalho que mescla apoio e aprendizagem, uma prática de saúde que une o cuidar e o pensar, buscando transformar os pacientes de "receptores passivos dos cuidados em saúde em co-autores dos resultados, procurando fazer com que utilizem, que 'se encarreguem' de suas potencialidades como seres humanos (Bleger, 1998, p.59). Esse direcionamento faz com que, em determinados momentos, "o grupo torne-se um ambiente composto por vários pacientes, com vários terapeutas, já que os pacientes exercem, reciprocamente, um papel terapêutico em diversas 
ocasiões" (Mello Filho, 2000, p.139), caracterizando um mecanismo de interação que institui a cultura do cuidado como um caminho para a adesão ao tratamento.

Assim como o cuidado, no grupo adesão a aprendizagem e o ensino são bilaterais, integrantes de um processo mútuo e solidário, no qual todos ensinam e todos aprendem, assemelhando-se a um processo pedagógico baseado na exemplaridade, na simetria, na interação e na reciprocidade que permite aos seres humanos, reunidos naquele ambiente, colocarem-se uns frente aos outros, aprenderem uns com os outros, encurtando a distância entre profissionais e pacientes em uma aproximação que possibilita diminuir o fosso entre os serviços de saúde e o cotidiano da população assistida.

Este ambiente marcado pelo zelo e pela conscientização baseia-se em uma proposta de atenção comprometida com a solidariedade e com a cidadania. Esta combinação cria um campo atravessado por conceitos e princípios que se articulam e que são representados pelo princípio da integralidade, pela dinâmica dos grupos operativos de Pichon-Rivière (1982), pelo processo de ensinar e aprender sob a ótica de José Bleger, e ainda pela proposta de ensino-aprendizagem de Paulo Freire.

Do princípio da integralidade vem o entendimento do homem biopsicossocial que se estrutura como sujeito pela estreita interação de suas diversas dimensões e por suas relações com o meio. Esta concepção que considera o indivíduo em sua totalidade orienta o entendimento do processo saúde/doença incidindo sobre a prática dos profissionais de saúde, influenciando seu modo de tratar o paciente e colocando o foco da atenção na pessoa e não na doença. Como um princípio orientador, transforma as relações de quem cuida com quem é cuidado, na medida em que a partir dele a impessoalidade da relação sujeito-objeto dá lugar à relação sujeito-sujeito, possibilitando aproximações mais compromissadas e humanizadas. Essa aproximação permite o conhecimento recíproco e abre caminho para o diálogo, por meio do qual se constrói uma relação interpessoal que "descoisifica" os sujeitos, possibilita perceber diversidades, cria vínculos, facilita a compreensão das necessidades de quem sofre e influencia o processo de trabalho $e$ as ações de saúde.

Complementarmente, da Psicologia vem a contribuição no sentido de formatar a prática aqui apresentada, configurada por um grupo homogêneo ${ }^{4}$, com uma estrutura ${ }^{5}$ na qual as pessoas se aproximam, se vinculam e interagem, estabelecendo uma relação dialógica que opera a integração do conhecimento intelectual com a vivência, o que facilita a transformação da atitude perante o cuidado com a saúde naquilo que chamamos grupo operativo com finalidade terapêutica.

A grupoterapia com pacientes portadores de doenças crônicas nos serviços de saúde é uma prática assistencial secular que varia em múltiplas modalidades, moldadas pela finalidade, pela técnica e pela fundamentação teórica. Os procedimentos terapêuticos e as ferramentas técnicas variam e combinam-se de acordo com o objetivo do trabalho grupal. Neste ensaio, o grupo em questão é o de pacientes somáticos, um grupo operativo que mescla terapêutica e ensino-aprendizagem e cuja finalidade é promover a adesão ao tratamento. Esta prática assistencial é terapêutica e pedagógica
${ }^{4}$ Assim, no campo da saúde, os grupos de atendimento a paciente somático são classificados por Mello Filho (2000, p.432) em homogêneos $e$ heterogêneos. São denominados homogêneos os grupos que reúnem pessoas com enfermidade comum (grupos de hipertensos

diabéticos, pacientes HIV+) e heterogêneos aqueles que apresentam doenças diferentes.

5 "Estrutura é o conjunto de vínculos que une um grupo" (Oliveira Júnior, 1997 p.56), diz respeito à intencionalidade de um grupo, ao objetivo comum, a

determinados tipos de laços, relações, papéis. 
${ }^{6} \mathrm{~A}$ proposta de Freire parte do Estudo da Realidade (fala do educando) e a

Organização dos Dados (fala do educador). Nesse processo surgem os Temas Geradores, extraídos da problematização da prática de vida dos educandos. Os conteúdos de ensino são resultados de uma metodologia dialógica. Cada pessoa, cada grupo envolvido na ação pedagógica dispõe em si próprio, ainda que de forma rudimentar, dos conteúdos necessários dos quais se parte (Feitosa,1999). por possibilitar a ampliação da consciência sobre a doença, potencializar a capacidade humana de superar dificuldades, promover transformação da atitude perante o processo saúde-doença, e propiciar aprendizagem mútua e recíproca à medida que quando se trabalha uma determinada situação não é só a situação que se modifica, mas também o sujeito que, transformado, contribui para modificar a situação.

Grupo operativo, conceituado e sistematizado por Pichon Rivière, de acordo com Zimerman \& Ozório (1997, p.76), pode ser definido, então, como um conjunto de pessoas que tentam operar como equipe com o objetivo comum de realizar uma determinada tarefa, razão pela qual este tipo de grupo é considerado um continente de todos os demais grupos, os terapêuticos e aqueles que lidam nos campos de ensino-aprendizagem, comunitários, institucionais, dando origem a ramificações que se interpõem $e$ se complementam.

Esse processo interativo de pessoas e conhecimentos apoia-se no método dialógico, participativo, evidenciando uma bilateralidade em que o sujeito afeta e é afetado, confirmando que ensino e aprendizagem são "passos dialéticos e inseparáveis, integrantes de um processo único em permanente movimento" (Bleger, 1998, p.56), concepção que na Pedagogia fundamentase no método de Paulo Freire ${ }^{6}$ para orientar o procedimento na ação, levando em conta, principalmente, o respeito ao educando, a conquista da autonomia e a plena dialogicidade.

Com base nessa proposta pedagógica, a tarefa a ser realizada no grupo adesão parte da realidade dos pacientes, dos fatos de sua vida cotidiana que emergem à medida que o grupo se desenvolve e o vínculo se estabelece entre as pessoas; então, as experiências trazidas são discutidas, valorizadas, associadas à questão saúde/doença, dando oportunidade de desvelar aspectos desta situação que poderiam passar despercebidos pelos atores envolvidos, tornando infecunda a ação em prol da saúde.

A relação dialógica estabelecida no ambiente grupal permite perceber os conteúdos de diversas naturezas que fazem parte do processo saúde-doença $e$ contextualiza o paciente na ação de saúde, criando para os facilitadores do grupo adesão oportunidade de integrar os diferentes aspectos contidos naquele processo à finalidade do trabalho. Este tipo de fazer a ação encontra respaldo nas idéias de Freire (1997, p.70) ao afirmar que "não há pensamento que não esteja referido à realidade, direta ou indiretamente marcado por ela, do que resulta que a linguagem que o exprime não pode estar isenta destas marcas”. Em síntese, os conceitos e os princípios que se inter-relacionam e se complementam são os pilares que dão sustentação à prática de saúde aqui apresentada: grupo adesão como espaço de ensino e de aprendizagem, no qual se desenvolve uma ação de saúde baseada no diálogo, que prioriza o homem e valoriza a potencialidade humana, que permite entrar em contato com outros modos de pensar e viver a vida e traz para o cotidiano dos serviços de saúde a possibilidade de discutir problemas importantes que estejam dificultando a adesão ao tratamento.

O pensar sobre o fazer

Na prática com grupo adesão, considerada dinâmica, que possibilita o 
contato efetivo e afetivo com diferentes pessoas, questionam-se certezas, mobilizam-se conhecimentos, provocam-se sentimentos, influenciam-se atitudes e maneiras de pensar, razão pela qual é de fundamental importância que sejam criados momentos de reflexão sobre o trabalho que os profissionais desenvolvem.

Por entender que é "pensando criticamente a prática de hoje ou de ontem que se pode melhorar a próxima prática" (Freire, 1996, p.43), propõe-se a ocorrência sistemática, em paralelo ao grupo com pacientes, com uma regularidade previamente combinada, de reuniões de reflexão sobre o trabalho com os facilitadores, momentos considerados de avaliação. Nestas reuniões, coordenadas por um profissional de saúde mental experiente no manejo de grupos, podem-se perceber os rumos do trabalho, viabilizar possíveis correções, acompanhar a consonância dos objetivos traçados em relação ao trabalho desenvolvido, pensar alternativas para transpor dificuldades, discutir e tomar decisões.

É o momento de pensar sobre o que se faz, de consolidar, sistematizar e aprender com o trabalho, pois se para Freire (1997, p.13) o "diálogo é a base da educação", para Bleger (1998, p.64), "pensar é o eixo da aprendizagem"; portanto, refletir sobre o que se pratica promove a ampliação da capacidade de análise e de intervenção no campo em que se atua.

É o momento de reconhecer e analisar os conteúdos subjetivos e objetivos do trabalho que vem sendo realizado tais como: ansiedades, medo de perder a identidade, esclarecimentos e busca de sintonia no desempenho da tarefa, reforço da alternância de papéis na equipe de coordenação, discussão sobre situações de dificuldade encontradas na condução do grupo, na relação da equipe e a busca de rumos para solucioná-las.

É quando se explicita a interação ideológica e afetiva da equipe, que se unem reflexão e ação, criando um campo propício ao desenvolvimento de potencialidades que geram novas estratégias e parcerias baseadas na solidariedade e não na competitividade; quando se rompe a cisão entre teoria e prática, serviço e aprendizagem, momento, portanto, de romper a divisão entre pensar e fazer, pois

(...) A divisão entre o pensar e o fazer, ao longo da história do homem, é um excitante desafio que permanece, exigindo exames cada vez mais aprofundados. As ações de saúde e a formação de recursos humanos nessa área não estão imunes a essa cisão. A formação acadêmica evidencia as dificuldades de trabalho, priorizando ora a prática ora a teoria (...). Essa nociva dicotomia tem mobilizado o pensar, que na falta de retroalimentação da realidade do meio, está mais próxima do verbalismo que da teorização. Em contrapartida, a prática, pouco crítica e alijada do pensar, tem se transformado num ativismo não reflexivo. (Rezende, 1989, p.9)

O processo de "ensinagem"

A prática do grupo adesão é norteada pela concepção de educação em que o 


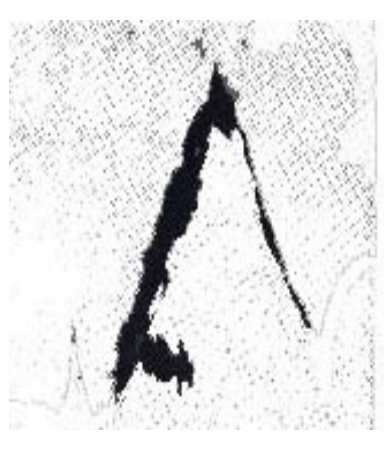

homem é um ser de relações em constante interação, integralmente incluído em tudo aquilo que ele participa, "(...) que ele sente, percebe e sobre a qual exerce uma prática transformadora" (Freire, 1997, p.75), relações de ambivalência, simbolismos, diferenças que dão ao homem a dimensão humana do próprio homem. Ao incluir a dimensão humana nas ações terapêuticas e pedagógicas, percebe-se uma dinâmica, como foi anunciado anteriormente, na qual o sujeito afeta e é afetado, caracterizando um processo de influência mútua. Neste processo, a relação interpessoal é uma via, um instrumento, um recurso a ser incorporado e utilizado no cuidado $e$ na aprendizagem. O resultado desta dinâmica é uma dupla humanização em que a prática humaniza os sujeitos e os sujeitos humanizam a prática que desenvolvem, entendimento que se reforça no pensamento de Bleger (1998, p.62) ao afirmar que "quando se trabalha um objeto, não apenas o objeto está sendo modificado, mas também o sujeito (...), e as duas coisas ocorrem ao mesmo tempo".

É nesta perspectiva dialética que se afirma o grupo adesão enquanto espaço pedagógico, no qual o processo de ensino e de aprendizagem é bilateral, acontece em mão dupla, construído em bases de reciprocidade entre pessoas e saberes, que se reforça na premissa de que "não existe ser humano que não possa ensinar algo, quando mais não seja pelo simples fato de ter certa experiência de vida" (Bleger (1998, p.58). Se, no grupo adesão, há momentos em que na cena há vários sujeitos que se cuidam entre si, há também esta dinâmica no que diz respeito a ensinar e aprender. E nestes momentos, em que ensino e aprendizagem, passos dialéticos e inseparáveis, solidariamente relacionados se fundem, gerando um processo único em permanente movimento, caracteriza-se uma ação que Bleger (1998, p.59) denominou de "ensinagem". Neste processo o aprender/ensinar não tem o sentido limitado de recolher, transmitir informação, mas sim converter em ensino e aprendizagem toda conduta e experiência, relação ou ocupação, energizando a capacidade dos participantes para que se encarreguem, dinamizem suas potencialidades como seres humanos.

No ambiente do grupo adesão, as pessoas estão em busca de aprender, de facilitar e se ajustar a um acontecimento que evidencia seu processo saúdel doença e elas "aprendem, com sua participação direta, a problematizar e a empregar os instrumentos para encontrar soluções e estabelecer as possíveis vias de solução” (Bleger, 1998, p.61). E os profissionais de saúde que ali estão percebem que sua função, como facilitadores de grupo que se propõem a contribuir para que os pacientes se vinculem ao tratamento, é acolhê-los e ouvi-los para que tragam experiências, situações vividas, dúvidas, por meio das quais se explicitem as dificuldades em cuidar-se, identifiquem quais os recursos de que dispõem para dar conta deste seu momento e então estabeleçam conexões entre os conhecimentos, as informações $e$ as vivências, para que novos entendimentos possam processar novas formas de condutas em prol da saúde, oportunizando uma "aprendizagem vital que pressupõe uma mudança de atitude a respeito da pessoa inteira" (Folkes \& Anthony, 1972, p.14).

Tal qual a relação que se estabelece entre professores e alunos, a relação entre facilitadores e pacientes no grupo adesão é, portanto, sempre uma 
relação pedagógica porque o espaço de convívio é mediado por conhecimentos que são, intencionalmente, ensinados e aprendidos, desconstruídos, construídos e/ou reconstruídos em atividades que os colocam frente a frente produzindo teorias, discutindo conceitos e experiências, criando novos fatos, enfim, interagindo, valorizando a contribuição de cada um e de todos, produzindo momentos de "ensinagem", "de modéstia e humildade no conhecimento, e das limitações humanas frente ao desconhecido" (Bleger, 1998, p.77).

Tal qual entre professor e aluno, também a relação de reciprocidade entre profissionais e pacientes no grupo adesão não significa total igualdade de papéis. O profissional tem sua função e nela, por vezes, ocupa o lugar de "suposto saber" em que o paciente o coloca. No entanto, a convivência propicia ao profissional uma tomada progressiva de consciência que the permite perceber que sabe (ou deveria saber) sobre sua especificidade profissional, e com humildade para reconhecer que quem sabe sobre si mesmo é o paciente. Contudo, isso não lhe retira a possibilidade de aprender com e no grupo e de assumir-se como parceiro no processo de adesão ao tratamento.

Nesse sentido, a formação de profissionais de saúde deve, por um lado, necessariamente incluir um momento no qual sejam feitas reflexão e crítica sobre as formas e o significado de ensinar, de trazer o outro para sua perspectiva e com ele também aprender, um momento de experimentar situações desse acontecimento "feiticeiro" que se chama trabalhar em grupo para facilitar a adesão ao tratamento; por outro, deve ensejar a compreensão da complexidade do processo de formação e de seus determinantes, que transcendem, e muito, o espaço do próprio grupo e apontam possibilidades para sua transformação, fomentada em processos de ensino-aprendizagem em que o falar, o pensar, o sentir e o agir coexistem, sucedem-se e potencializam-se, e que se fundamenta na "crença de que os homens podem fazer e refazer as coisas; podem transformar o mundo" (Freire, 1977, p.74).

Portanto, pela possibilidade que oferece ao profissional de saúde de exercer sua função transformadora com resolutividade e responsabilidade social e também de produzir alternativas que respondam aos desafios na busca de adesão ao tratamento, consideramos a prática com grupo adesão como um espaço de aprendizagem no qual os sujeitos que dele compartilham, de acordo com Rovere (1992, p.12), "são problematizados e problematizam uma determinada realidade desenvolvendo competências para intervir sobre ela".

Com o propósito de ouvir o que pensam a esse respeito os profissionais de saúde que atuam em grupo adesão, respaldando o estudo teórico que estamos apresentando, a eles foi perguntado, em um primeiro momento, se consideravam o grupo um cenário de aprendizagem para pacientes e, em um segundo momento, se o consideravam um cenário de aprendizagem para profissionais de saúde. Em unanimidade, os facilitadores avaliaram ser este cenário propício à aprendizagem bilateral, de profissionais e pacientes, o que reforça a hipótese levantada no decorrer desse trabalho e que foi anunciado pelos entrevistados: [o grupo] é importante para o paciente e para o profissional, que se capacitam mutuamente. 
Cabe notar que no grupo adesão ensinar e aprender estão articulados desde sua concepção, quando se discute como será o grupo, quando se planeja a atuação no grupo, quando se busca estratégia de divulgação, quando se divulga o trabalho, ações que parecem simples, mas que foram apontadas pelos entrevistados como uma lacuna que mostra a necessidade de mudança na formação profissional.

Aprende-se e ensina-se no grupo a se aproximar das pessoas, a estabelecer relação como sujeitos, a interagir respeitando regras de convivência e o saber do outro, a observar e escutar, a se comunicar dialogando, a emitir opiniões explicitando conflitos e buscando consenso, a admitir que outros pensem de modo diferente, a perceber o que se diz e o que realmente se faz porque é [um momento] mais real do que a consulta individual.

Aprende-se e ensina-se com o grupo a compartilhar conhecimentos e a incorporar novos saberes e práticas, a facilitar e simplificar as informações, a compreender a comunicação humana nas sutilezas da expressão dos afetos, a se desarmar para receber o outro, a lidar com situações de imprevisibilidade e a deixar fluir o potencial criativo, a problematizar, a indagar, a ser crítico, porque ali a vida acontece.

Aprende-se e ensina-se no grupo a trabalhar em equipe, a viver e conviver com o outro, a estabelecer parcerias, a reconhecer as capacidades e os limites dos colegas e dos pacientes, a ter esperança e crença, "(...) a crença em que os homens podem fazer e refazer as coisas; podem transformar o mundo" (Freire, 1997, p.74). Para os profissionais entrevistados, o trabalho em grupo adesão representa uma mudança no trabalho que se reflete na vida pessoal.

\section{Considerações finais}

Como demonstrado no decorrer deste ensaio, o trabalho com grupos em unidades de saúde é um recurso potencial para ser incorporado pelas instituições e pelos profissionais no desempenho da tarefa de promover saúde. Uma atividade que procura dar aproveitamento a todos os recursos com que conta cada pessoa na busca por viver melhor, que otimiza recursos financeiros e o período de trabalho dos profissionais, que potencializa a ação de saúde tendo, ainda, aplicação pedagógica na formação e no aprimoramento profissional de quem a desempenha é, sem dúvida, uma atividade a ser exercida amplamente para o bem público.

Trata-se de uma prática secular que alia condições vantajosas com situações problemáticas e por ser uma prática não instituída com regularidade nos serviços de saúde, o trabalho com grupos de pacientes crônicos, por vezes, caracteriza-se por uma iniciativa ingênua, na qual os profissionais têm boa vontade para desempenhar a ação, mas não estão

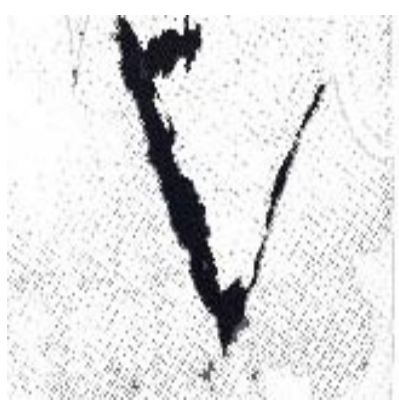
capacitados a fazê-la com suficiente rigor teórico e criticidade, caindo no paternalismo gerador de dependência, em que alguns colocam-se como foco da ação e, na ausência deste profissional, o trabalho não vai adiante. Portanto, trata-se de uma prática que para ser realizada exige profissionais competentes, do ponto de vista de conhecimentos, habilidades e atitudes, que se não exercitados deixam de ser incorporados uma vez que se trata de uma prática que capacita pelo desempenho: o aprender fazendo e o fazer aprendendo. 
Sobre as práticas grupais, Luz (2001, p.34) assinala que

(...) há uma tendência ascendente em incluir tais práticas na rede pública de serviços, sendo propiciada pela política de saúde descentralizadora vigente no país. A tendência ao crescimento desta incorporação está estreitamente ligada, a meu ver, ao papel que a cidadania poderá representar na descentralização das políticas públicas nos próximos anos.

Porém, a institucionalização deste tipo de prática, pressupõe mudança; $e$ seria ingenuidade supor mudança apenas no processo de formação profissional. Pressupõe, antes de tudo, mudança de atitude dos homens perante os outros homens e, aqui, não estamos falando apenas nas relações que se estabelecem na atividade de trabalho; pressupõe mudança nos homens, fundamentalmente na forma como se percebem na vida, como bem traduz Bleger (1998, p.112):

(...) Sei que não ofereço soluções fáceis e às vezes nem sequer soluções difíceis, mas as soluções só podem emergir, no melhor dos casos, de uma proposição correta dos problemas que devemos enfrentar, e com isto entendo, assim mesmo, que estamos envolvidos como agentes de mudança, mas, também, como agentes que asseguram uma organização que constitui uma resistência à mudança.

Pelas razões apresentadas, o grupo adesão, que evidencia a riqueza da variedade humana, propicia a compreensão do homem como um ser integral, do processo saúde-doença e seus determinantes, do conceito de saúde em uma perspectiva ampliada, e cria condições para a interação dos participantes, permite ampliar a capacidade dos profissionais de trabalhar junto e há de ser entendido como espaço de ensino e de aprendizagem, um espaço de "ensinagem".

Cabe um insistente reforço e disseminação desta concepção, de modo a beneficiar um maior número de pessoas com práticas humanizada e coletiva na atenção à saúde.

Diante do exposto, ficam-nos algumas questões: em quê a universidade pode contribuir para concretizar uma prática que tem se revelado eficaz? Se pode, por que ainda não a incorporou aos currículos da área da saúde? As Diretrizes Curriculares para a área da saúde estão homologadas pelo Ministério da Educação desde 2001 (Brasil, 2001). Qual notícia temos de movimentos que pretendem se aproximar desta concepção de prática coletiva, humanizada, igualitária que, além de partir da realidade das pessoas que recebem cuidado, retroalimentam a formação profissional?

Estas e outras questões ficam como indagações para nós, da saúde e da educação, que acreditamos no potencial dos homens. E servem para outros estudos que talvez possam se valer daquilo que foi apresentado neste trabalho. 
GRUPO DE ADESÃO AO TRATAMENTO: ESPAÇO...

\section{Referências}

BLEGER, J. Temas de psicologia: entrevista e grupos. São Paulo: Martins Fontes, 1998.

BOTEGA, N. J. Prática psiquiátrica no hospital geral. Porto Alegre: Artmed, 2001.

BRASIL, CNE/CES. Parecer $n^{\circ} 1.133 / 2001$. Diretrizes curriculares nacionais dos cursos de graduação em enfermagem, medicina e nutrição. Brasília: MEC, 2001.

DEVEZA, M. Saúde para todos: médicos para o ano 2000? 1983. Dissertação (Mestrado) - Instituto de Medicina Social, Universidade do Estado do Rio de Janeiro, Rio de Janeiro.

FEITOSA, S.C.S. Método Paulo Freire: princípios e práticas de uma concepção popular de Educação. 1999. Dissertação (Mestrado) - Faculdade de Educação, Universidade de São Paulo, São Paulo.

FEUERWERKER, L.C.M. Estratégias para a mudança da formação dos profissionais de saúde. Caderno CE, v..2, n.4, p. 11-23, 2001.

FLETCHER, R. H.; FLETCHER, S.W.; WAGNER, E. Epidemiologia clínica. Porto Alegre: Artes Médicas, 1989.

FOLKES, S.H.; ANTHONY, E.J. Psicoterapia de grupo. São Paulo: IBRASA, 1972.

FREIRE, P. Pedagogia da autonomia: saberes necessários à prática educativa. São Paulo: Paz e Terra, 1996.

FREIRE, P. Extensão ou Comunicação? São Paulo: Paz e Terra, 1997.

OLIVEIRA JÚNIOR, J. F. Grupoterapia: teoria e prática. São Paulo: SPAG-CAMP, 1997.

LUZ, M. T. Políticas de descentralização e cidadania: novas práticas de saúde no Brasil atual. In: PINHEIRO, R.; MATTOS, R. A. (Orgs.) Os sentidos da integralidade na atenção e no cuidado à saúde. Rio de Janeiro: IMS/UERJ/ABRASCO, 2001. p.17-37.

MELLO FILHO, J. Grupo e corpo: psicoterapia de grupo com pacientes somáticos. Porto Alegre: Artes Médicas, 2000.

PICHON-RIVIÈRE, E. O processo grupal. São Paulo: Martins Fontes, 1982.

REZENDE, A.L.M. Saúde, dialética do pensar e do fazer. São Paulo: Cortez, 1989.

RODRIGUES, R.D. A crise da medicina: prática e saber - alguns aspectos. 1979. Dissertação (Mestrado) - Instituto de Medicina Social, Universidade Estadual do Rio de Janeiro, Rio de Janeiro.

ROVERE, M.R. Planificacion estrategica de recursos humanos en salud. Programa de Desarrollo de Recursos Humanos de Salud. OPAS, 1992.

ZIMERMAN, D.E.; OZÓRIO, L.C. Como trabalhamos com grupos. Porto Alegre: Artes Médicas Sul, 1997.

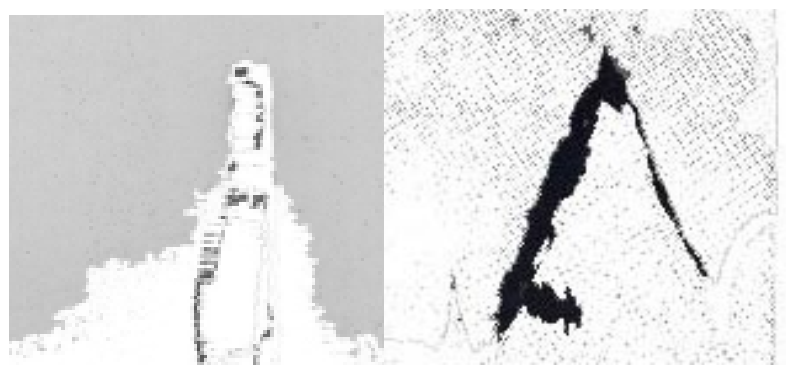




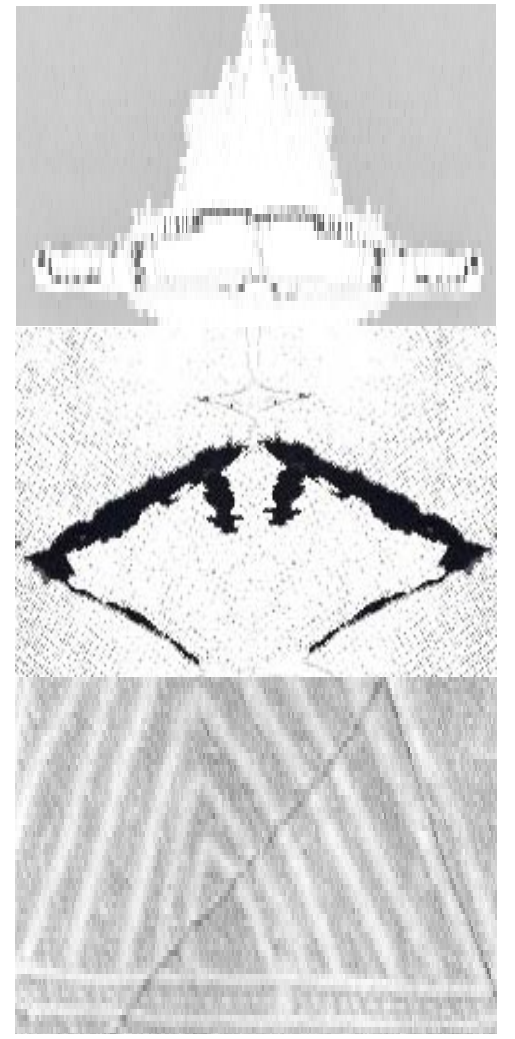

SILVEIRA, L. M. C.; RIBEIRO, V. M. B. Grupo de adhesión al tratamiento: espacio de "enseñanza" para profesionales de la salud y pacientes, Interface - Comunic., Saúde, Educ., v.9, n.16, p.91-104, set.2004/fev.2005.

El ensayo presenta una práctica de atención a la salud -Grupos de Adhesión al Tratamientoque han evidenciado un campo potencial de terapéutica, de enseñanza y de aprendizaje a pacientes y a profesionales de la salud. Esto se trata de un escenario de interacción de personas diferentes, conceptos, valores y culturas donde cada personaje se diferencia y se reconoce en el otro por medio de dinámicas en que sea posible hablar, escuchar, sentir, indagar, reflexionar y aprender a pensar. Se caracteriza por ser un grupo informativo, reflexivo y de soporte, homogéneo en lo que se refiere a la enfermedad de los pacientes, coordinado por dos o más profesionales de salud de diferentes categorías, que por medio del método "dialógico" tiene como objetivo facilitar la adhesión de los pacientes al tratamiento.

PALABRAS CLAVE: Practicas en terapia de grupo; adhesion al tratamiento; espacio de enseño y de aprendizaje; equipo multidisciplinar en salud. 